Word count: 6,026

Abstract: 249

Figures: 3

Tables: 2

\title{
Early life stress, FKBP5 polymorphisms and quantitative glycemic traits
}

$$
\begin{aligned}
& \text { Anna Suarez, MA*a , Jari Lahti, PhD }{ }^{\text {a,b, c }} \text {, Eero Kajantie, MD, PhD }{ }^{d, e, f} \text {, } \\
& \text { Johan G. Eriksson, MD, DMSc }{ }^{\text {b,d,g }} \text { \& Katri Räikkönen, } \mathrm{PhD}^{\mathrm{a}}
\end{aligned}
$$

Short title: Early life stress, FKBP5 and glycemic traits

\section{Corresponding author:}

Anna Suarez, Institute of Behavioural Sciences, University of Helsinki, Siltavuorenpenger 1-5, PO Box 9, FI-00014 University of Helsinki, Finland. Tel: +358 407738 113. Fax: +358 9412 9539. Email: anna.suarez@helsinki.fi.

\section{Affiliations:}

${ }^{a}$ : Institute of Behavioural Sciences, University of Helsinki, Helsinki, Finland; ${ }^{\text {b: }}$ Folkhälsan Research Center, Helsinki, Finland; ': Helsinki Collegium for Advanced Studies, University

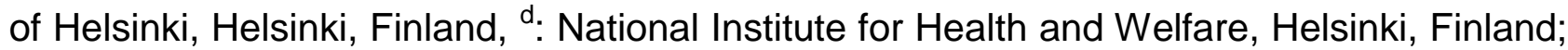
e : Hospital for Children and Adolescents, Helsinki University Hospital and University of Helsinki, Helsinki, Finland; ${ }^{\dagger}$ : PEDEGO Research Unit, Oulu University Hospital and University of Oulu, Oulu, Finland; ${ }^{\text {g: }}$ Department of General Practice and Primary Health Care, University of Helsinki and Helsinki University Hospital, Helsinki, Finland

\section{Conflicts of Interest and Source of Funding:}

Authors report no conflicts of interest. 


\section{Abstract}

Objective. Early life stress (ELS) has been shown to influence health later in life. Functioning of the hypothalamic-pituitary-adrenal (HPA) axis, regulated partly by FKBP5 gene, may moderate these effects. We examined whether FKBP5 single nucleotide polymorphisms (SNPs) interact with ELS on type 2 diabetes, cardiovascular disease, and quantitative glycemic traits.

Methods. 1,728 Helsinki Birth Cohort Study participants born 1934-44 were genotyped for FKBP5 SNPs (rs1360780, rs9394309, rs9470080), administered a 2-h (75 g) oral glucose tolerance test and a questionnaire on physician-diagnosed and medication use for chronic diseases at a mean age of 61.5 years. Of them 273 were exposed to ELS, namely were separated from their parents at a mean age of 4.7 years due to evacuations during WWII.

Results. ELS interacted with FKBP5 SNPs in the analyses of fasting (rs1360780, p=.015), 30-min (rs1360780, $\mathrm{p}=.031 ; \mathrm{rs} 9394309, \mathrm{p}=.041$ ) and incremental insulin (rs1360780, $\mathrm{p}=.032 ; \mathrm{rs} 9394309, \mathrm{p}=.028 ; \mathrm{rs} 9470080, \mathrm{p}=.043$ ), insulin area under the curve (rs1360780, $\mathrm{p}=.044$ ), and impaired fasting glucose (IFG) (rs9470080, $\mathrm{p}=.049$ ); among carriers of at least one copy of minor allele, but not among major allele homozygotes, insulin values were higher as were the odds for IFG if they were separated compared to if they were not. Corresponding associations were found with a haplotype formed by minor alleles in all three SNPs for fasting, 30-min, and incremental insulin ( $p<.05)$.

Conclusions. FKBP5 polymorphisms in combination with ELS exposure predict higher insulin and glucose values in midlife. Our findings support the role for HPA axis dysregulation in health-related metabolic outcomes.

Keywords: early life stress; insulin; diabetes; FKBP5; HPA axis; gene-environment interactions 
AUC $=$ Area Under the Curve, $\mathbf{B M I}=$ Body Mass Index, $\mathbf{C V D}=$ Cardiovascular Disease

ELS = Early Life Stress, GxE = Gene-environment interaction, $\mathbf{G R}=$ Glucocorticoid Receptor, HBCS = Helsinki Birth Cohort Study, $\mathbf{H O M A}_{\mathbf{I R}}=$ Homeostasis Model Assessment Method, HPA axis = Hypothalamic-Pituitary-Adrenal axis, IFG = Impaired Fasting Glucose, IGT = Impaired Glucose Tolerance, ISI = Inulin Sensitivity Index, $\mathbf{m T O R}$ = Mammalian Target of Rapamycin, OGTT = Oral Glucose Tolerance Test, SNP $=$ Single Nucleotide Polymorphism, T2D = Type 2 Diabetes, $\mathbf{W H O}=$ World Health Organization, WWII = World War II 


\section{Introduction}

Adversities experienced early in life (early life stress; ELS), such as abuse, neglect, and separation from parents due to parental death, divorce or war, have been shown to increase the risk for psychiatric disorders $(1,2)$. Emerging data suggests that ELS is also associated with obesity and increased risk for cardiovascular diseases (CVD) and type 2 diabetes (T2D) (3-5).

While the mechanisms underlying these associations remain elusive, it has been suggested that ELS may exert its effects via functioning of the hypothalamic-pituitaryadrenal (HPA) axis. Although this pathway is biologically highly plausible (6), empirical data supporting the association between plasma or serum cortisol levels, end products of HPA axis activity, with CVD, T2D and glycemic traits have been inconsistent (7-9). We are not either aware of studies testing interactions between ELS and HPA axis hormonal products on CVD, T2D and glycemic traits.

Apart from HPA axis hormonal products, focus on genes that participate in the HPA axis regulation may provide an alternate avenue to gain insight into the ELS pathway to disease. One key player participating in the HPA axis regulation is FKBP5 gene. FKBP5 codes for the FK506 binding protein 51, a heat shock protein 90 co-chaperone (10). It participates in inhibition of the glucocorticoid receptor (GR) activity, which is the main regulator of the HPA axis activity (10), while GR activation induces FKBP5 transcription via steroid hormone response elements (11). Thus, FKBP5 forms an intracellular negative feedback loop which regulates the GR sensitivity and, simultaneously, is responsive to stressful exposures, making it a promising candidate for gene-environment (GxE) interaction studies (12).

The best investigated single nucleotide polymorphisms (SNP) belong to functional haplotype spanning the whole FKBP5 gene (from the promoter area to the 3'UTB in 
Caucasians) that is tagged by rs3800373, rs9296158, or rs 1360780 and contains up to 18 polymorphisms, which are in strong LD with the tagging SNP (12). Indeed, a series of studies have demonstrated that FKBP5 polymorphisms from this haplotype were associated with HPA-axis reactivity: adults homozygous for minor alleles in rs 1360780 (TT), rs3800373 (GG), and rs4713916 (AA) had elevated recovery plasma cortisol in response to Trier Social Stress Test (TSST) (13) and infants who had one or two copies of minor T-allele of rs1360780 had elevated salivary cortisol in response to Strange Situation Procedure (SSP) (14). Furthermore, adults who were exposed to ELS and had one or two copies of minor allele in rs1360780 (T), rs9296158 (A), rs9470080 (T), rs9394309 (G), or rs3800373 (C) had elevated risk of depression and subclinical symptoms (15-17) and PTSD (2).

However, we are aware of only one study that to date has examined whether FKBP5 SNPs interact with ELS on physical health outcomes: carriers of one or two minor T-alleles of rs1360780 were at increased risk for self-reported physician-diagnosed physical problems if they retrospectively reported exposure to physical, emotional or sexual abuse in childhood, but not if they were homozygous major C-allele carriers (18). Yet, the extent to which FKBP5 polymorphisms interact with ELS in predicting CVD, T2D, and quantitative glycemic traits remains unknown.

Accordingly, we examined if ELS, defined here as temporary separation from both biological parents due to child evacuations during World War II (WWII), interacted with three selected common FKBP5 SNPs (rs1360780, rs9394309, rs9470080) in predicting CVD, T2D, and quantitative glycemic traits in midlife.

\section{Methods}

\section{Participants}


The Helsinki Birth Cohort Study (HBCS) includes 13345 Caucasian individuals who were born in Helsinki, Finland between 1934 and 1944, and were alive living in Finland in1971 when a unique personal identification number was allocated to each member of the Finnish population $(19,20)$.

Between 2001 and 2004, a random subset of 2,902 individuals was invited and 2,003 (69\%; 1,075 women and 928 men) participated in a clinical exam during which blood samples for DNA were obtained (Mean age=61.5 years, $S D=2.9)(19,20)$. Genotype data were available for 1,728 participants (275 individuals were not included in the genetic analyses due to gender discrepancy, relatedness, failure in DNA sampling, or refusal to participate in the genotyping). Of them 273 were separated from their biological parents during WWII as indicated by the National Archives Registry or self-report in conjunction with the clinical examination, as described below.

In comparison to those not included in the analytic sample, those included were more often women $(p<.001)$, had lower levels of 30 -minute glucose $(p<.05)$ and fasting insulin $(p<.001)$, but there were no differences in age, separation status, father's occupational status in childhood, CVD, T2D, or other insulin and glucose values. The study was carried out in accordance with the Declaration of Helsinki, the study protocol was approved by the Institutional Review Board of the National Public Health Institute. A written informed consent was obtained from all participants.

\section{Diabetes, CVD and quantitative glycemic traits}

In the morning after a 12-hour overnight fast, the participants were administered a $75 \mathrm{~g}$ oral glucose tolerance test (OGTT). During the OGTT, venous samples for plasma glucose and serum insulin were drawn at 0,30 , and 120 minutes. Plasma glucose was measured with a glucose dehydrogenase method (HemoCue, Ängelholm, Sweden) and 
serum insulin with a fluoroimmunoassay (Delphia; Perkin-Elmer Finland, Turku, Finland). During the same visit the participants filled in a questionnaire where they provided information about physician-diagnosed chronic diseases and use of medication for these diseases.

The participants were defined as having diabetes if they reported a physiciandiagnosed diabetes or use of antidiabetic medication or if they met the World Health Organization (WHO) (21) criteria for diabetes based on the OGTT (fasting plasma glucose $\geq 7.0 \mathrm{mmol} / \mathrm{l}$ or 2-h plasma glucose $\geq 11.1 \mathrm{mmol} / \mathrm{l}$ ); cardiovascular disease if they reported physician-diagnosed coronary heart disease and/or stroke; impaired fasting glucose (IFG) and impaired glucose tolerance (IGT) is they met the WHO criteria (21) (IFG: fasting plasma glucose 6.1 to $6.9 \mathrm{mmol} / \mathrm{l}$ and 2-h plasma glucose $<7.8 \mathrm{mmol} / \mathrm{l}$; IGT: fasting plasma glucose $<7.0 \mathrm{mmol} / \mathrm{l}$ and 2-h plasma glucose $\geq 7.8$ and $<11.1 \mathrm{mmol} / \mathrm{l}$ during the OGTT). The homeostasis model assessment method ( $\left.\mathrm{HOMA}_{\mathrm{IR}}\right)$ (22), Insulin Sensitivity Index (ISI) (23), Incremental insulin (24), and area under the curve (AUC) (23) were used as indices of insulin sensitivity and insulin secretion. The following formulas were used to calculate these variables: $\mathrm{HOMA}_{\mathrm{R}}=$ Fasting plasma insulin $[\mathrm{mU} / \mathrm{l}] \times$ fasting plasma glucose level $[\mathrm{mmol} / \mathrm{I} / 22.5 ; \mathrm{ISI}=10,000 / \sqrt{ }$ (fasting plasma glucose level $[\mathrm{mmol} / \mathrm{l}] \times$ fasting insulin $[\mathrm{mU} / \mathrm{l}]) \times($ mean OGTT glucose $[\mathrm{mmol} / \mathrm{l}] \times$ mean OGTT $[\mathrm{mU} / \mathrm{l}]$ insulin); Incremental insulin $=30-\mathrm{min}$ insulin $[\mathrm{mU} / \mathrm{l}]-$ fasting insulin $[\mathrm{mU} / \mathrm{l}]$; and AUC were calculated as follow: AUC insulin $=15 \times$ fasting plasma insulin $[\mathrm{mU} / \mathrm{l}]+15 \times 30-\mathrm{min}$ insulin $[\mathrm{mU} / \mathrm{l}]+45 \times 30-\mathrm{min}$ insulin [mU/l] $+45 \times 2$ h-insulin [mU/l]; AUC glucose $=15 \times$ fasting plasma glucose $[\mathrm{mmol} / \mathrm{l}]$ $+15 \times 30-$ min glucose $[\mathrm{mmol} / \mathrm{l}]+45 \times 30-$ min glucose $[\mathrm{mmol} / \mathrm{l}]+45 \times 2 \mathrm{~h}$-glucose $[\mathrm{mmol} / \mathrm{l}]$. 


\section{Early life stress}

Using the Finnish National Archives' registry (25), we identified 215 (12.4\%; 54.4\% women) participants in this study cohort who were separated temporarily from their parents in childhood. The mean age at separation was 4.7 years $(0.6-10.1)$ and the mean length of separation was 1.7 years (0.2-4.7). Data on age at and length of separation were available on a subset of 198 and 194 participants, respectively. The separations took place during WWII when nearly 80,000 Finnish children were evacuated from the strains of war to Sweden or Denmark without their biological parents (25).

Additionally, some children were evacuated without their parents either abroad or within homeland through personal contacts of the families: it has been estimated that this group may include over 20,000 children (25). A question addressing wartime separation from both parents was embedded in the survey at age 61.5 years when the participants attended the clinical examination. An additional 58 (3.4\%, 53.4\% women) participants selfreported as having been separated from both parents during WWII. Because of constraints that relate to memorizing events occurring at earliest stages in life and because events rather than sequences of timing of the same events are recalled more accurately (26), we did not use self-reported information on age at and length of separation.

\section{Genotyping and SNP selection}

Genotypes of intronal SNPs rs1360780, rs9394309, and rs9470080 were taken from the modified Illumina 610k array. These SNPs were selected using three criteria: their location in FKBP5 gene within functional haplotype (12); previously frequently reported significant GxE associations with risk of depression (15-17) and PTSD (2) in adulthood following ELS, and altered HPA-axis reactivity $(13,14)$; and MAF > $5 \%$ in this sample (see below). Genotyping was conducted at the Wellcome Trust Sanger Institute, Cambridge, UK according to standard protocols. Genotyping success rate was $>99 \%$ in all three 
SNPs analyzed in this study. Observed genotype frequencies did not deviate from the Hardy-Weinberg equilibrium ( $p>$.39). MAFs were $21.6 \%(C>T), 24.3 \%(A>G)$, and 25.6 $\%(C>T)$ for rs 1360780, rs9394309, and rs9470080, respectively. SNPs were in high LD in this sample $\left(r^{\wedge} 2: .72-.94\right)$, and according to the solid spine algorithm with default values, belonged to the same haploblock (Supplemental figure 1).

\section{Covariates and confounders}

Covariates included age at the time of clinical exam (yrs) and sex, father's occupational status in childhood derived from child welfare clinic and school health care records and categorized into three groups (lower, middle, upper), own maximum attained level of education in adulthood (basic/primary or less, lower secondary, upper secondary, or tertiary) recorded at 5-year intervals during the period $1970-2005$ by Statistics Finland, body-mass index (BMI) $\left(\mathrm{kg} / \mathrm{m}^{2}\right)$ as calculated from measured weight $(\mathrm{kg})$ and height $(\mathrm{m})$, depressive symptoms measured with the Beck Depression Inventory (BDI) (30), stressful life events the past 12 months measured using the Stressful Life Event Scale (31), and to control for population stratification, the first three multidimensional scaling (MDS) components were derived from multidimensional scaling analyses performed with Plink. In addition to using reported physician-diagnosed diabetes and antidiabetic medication use as part of the T2D diagnosis outcome, we used them as covariates in the analyses of glycemic traits.

\section{Statistical analyses}

Multiple linear regression analysis to examined if the three selected polymorphisms in FKBP5 gene, separation status and their interaction were associated with the continuous outcomes (fasting, 30-minute, 2-h, and AUC insulin and glucose, incremental 
insulin, ISI, and $\mathrm{HOMA}_{\mathrm{IR}}$ ) and logistic regression analysis examined these associations with the binary outcomes (IFG, IGT, T2D, and CVD). Each SNP was tested in separate model assuming both additive and dominant genetic effects. We further performed haplotype analysis, where rs1360780, rs9394309, and rs9470080 were analyzed within one haploblock in one model. Additionally, we tested whether length of (median split at 1.4 years; dummy coded with non-separated group as referent) and age at (median split at 3.9 years; dummy coded with non-separated group as referent) separation interacted with the three selected SNPs in predicting the continuous and binary outcomes. These analyses were not conducted with haplotype because of the smaller sample size.

All continuous variables were log-transformed to attain normality. All analyses were adjusted for covariates as described in results. We also made adjustments for SNP $x$ covariate and separation status $x$ covariate interactions (32).

The level of significance was set to $\alpha=0.05$. At this $\alpha$-level post hoc study power, computed using the observed power option in the multivariate general linear model test, varied from 0.050 to 0.64 . The SNPs were in high LD and belonged to one haploblock (Supplemental figure 1), while the outcomes were highly correlated between each other ( $r^{\wedge} 2: .66-.93$ and $r^{\wedge} 2:-.45-.99$ for glucose- and insulin-related outcomes, respectively). Principal component analysis revealed two factors with eigenvalue $>1$ explaining $82.2 \%$ of the total variance. Therefore, to correct for multiple testing we also present Bonferroni corrected $p$-values assuming two multiple tests.

IBM SPSS 24, Plink and R 3.2.2 software were used for the analyses. Linkage disequilibrium between the SNPs and haploblock structure was evaluated with Haploview 4.2 (33); analyses of haplotypes were performed with the Haplo.stats package 1.6 .11 of the R statistical software (34). 


\section{Results}

Characteristics of the sample according to the separation status are presented in Table 1. As we have reported previously (3), men and women were equally likely to have been separated from their parents, and in comparison to those who were not separated, those who were separated were slightly older at the time of testing in adulthood, but there were no significant differences in father's occupational status in childhood or BMI in adulthood between the groups (Table 1). In accordance to Alastalo et al (3) that used a slightly larger sample $(n=2,003)$ from which our genotyped sample $(n=1,728)$ was derived, the number of individuals with cardiovascular diseases $(p=.001)$ and with IGT $(p=.045)$ was significantly higher and the number of individuals with T2D trended to be higher $(p=.069)$ in the separated than in the non-separated group. However, in contrast to Pesonen et al (1) that used a slightly smaller $(n=1,681)$ than our genotyped sample and included father's military service or death in the frontier into the separation group and excluded it from the non-separated group, those separated did not differ from those not separated in depressive symptoms $(p=0.42)$. Because our definition of separation differed from that of Pesonen et al (1), we also ran analyses testing if the FKBP5 SNPS interacted with father's military service or death on CVD, T2DM or glycemic traits, and found no significant interactions ( $\mathrm{p}$-values>.06).

\section{FKBP5 polymorphisms $x$ ELS}

In the unadjusted models and in the models adjusted for covariates rs 1360780 interacted significantly with separation status in the analyses of fasting, 30-minute, incremental and AUC insulin (Figure 1), rs9394309 interacted significantly with separation status in the analyses of 30-minute and incremental insulin (Figure 2), and rs9470080 interacted significantly with separation status in the analysis of incremental insulin (Figure 3). Table 2 shows that across all the significant interactions, insulin values were higher 
among carriers of at least one copy of the minor allele if they were separated in comparison to if they were not; no differences between separated and non-separated groups existed among homozygous major allele carriers (for the analyses in Table 2 we combined carriers of one and two copies of minor alleles because the group of individuals homozygous for minor alleles in each of the SNPs in the separated group was small, $\mathrm{n}=$ 12 - 13). We re-ran the FKBP5 x ELS interaction analyses using dominant genetic model by contrasting those who were carriers of one or two minor alleles against homozygous major allele carriers and all the significant interactions that we found when using the additive genetic model remained ( $p$-values for interactions=.019-.036, Bonferroni-corrected $\mathrm{p}$-values $=.038-.072)$. In these analyses, however, we also found an additional significant interaction between rs9470080 and separation status with IFG (p-value for interaction=.049; Bonferroni-corrected $p$-value=.098): among carriers of at least one copy of minor allele the odds for IFG was higher in the separated $(n=87,20.3 \%)$ in comparison to the non-separated group $(n=535,13.4 \%)(O R=1.84,95 \% \mathrm{Cl} 0.97-3.52, p=.06)$; no such difference was found in homozygous major allele carriers $(\mathrm{OR}=0.68,95 \% \mathrm{Cl} 0.37-$ 1.25, $\mathrm{p}=.21)$

All the significant interactions remained unaffected when we made further adjustments for own maximum adulthood education ( $p$-values for interactions=.014-.037, Bonferroni-corrected $p$-values=.028-.074); similarly, the results remained virtually identical when we added depressive symptoms and stressful life events into the regression models, except in the analyses of IFG the interactions became slightly attenuated $(p=.062$ and .050 , Bonferroni-corrected $\mathrm{p}=.12$ and .098 , respectively). When additionally adjusted for antidiabetic medication and physician-diagnosed diabetes, the only interaction that remained significant was that of $r s 1360780 \times$ separation status on fasting insulin $(p=.009$, Bonferroni-corrected $\mathrm{p}=.018$ ). Also a previously non-significant interaction between 
rs1360780 $x$ separation status on HOMA-IR became significant $(p=.030$, Bonferronicorrected $\mathrm{p}=.059$ ). This interaction, in alignment with the others, showed that HOMA-IR values were higher among carriers of at least one copy of the minor allele if they were separated in comparison to if they were not, whereas no differences between separated and non-separated groups existed among homozygous major allele carriers (data not shown).

Haplotype analysis demonstrated that carriers of the haplotype formed by the minor alleles in rs1360780, rs9394309, and rs9470080 (19.6\% of individuals) who were separated from their parents showed higher levels of fasting ( $p$-values for interaction $=.048$, Bonferroni-corrected $\mathrm{p}=.096), 30-\mathrm{min}$ ( $\mathrm{p}$-values for interaction $=.032$, Bonferronicorrected $p=.064$ ), and incremental insulin ( $p$-values for interaction $=.021$, Bonferronicorrected $\mathrm{p}=.042$ ), thus, confirming our findings from the single SNPs $\mathrm{x}$ separation status analyses. None of the covariate adjustments affected these findings, except when adjusting for antidiabetic medication use and physician-diagnosed diabetes, only the results for fasting insulin remained unaffected $(p=.021)$; additionally, minor allele carriers of this haplotype showed higher levels of HOMA-IR $(p=.049)$.

The findings remained virtually identical when we made adjustments for the SNP $x$ covariate and separation status $x$ covariate interactions into the models (data not shown).

\section{FKBP5 polymorphisms $x$ length of and age at ELS}

Finally, we tested if the FKBP5 SNPs interacted with length of and age at separation. All three SNPs interacted with the length of separation in the analysis of fasting insulin ( $p$-values for interaction $=.010-.046$, Bonferroni-corrected $p$-values $=.020-.092$ ), such that fasting insulin values were higher among carriers of at least one copy of the minor allele if they were separated for median of 1.4 years or less in comparison to if they were not separated ( $p$-values<.024); no such differences existed among homozygous major 
allele carriers ( $p$-values $>$.65) (data not shown). Also all three SNPs interacted with the age at separation in the analyses of fasting insulin ( $p$-values for interaction=.008, Bonferronicorrected $p$-values=.016) and HOMA-IR ( $p$-values for interaction=.027-.043, Bonferronicorrected $p$-values $=.054-.086$ ), such that fasting insulin and HOMA-IR values were higher among carriers of at least one copy of the minor allele if they were separated at median age of 3.9 years or younger in comparison to if they were not separated ( $p$-values<.043); no such differences existed among homozygous major allele carriers ( $p$-values>.091) (data not shown). We did not pursue testing these interactions on CVD, T2D, IFG or IGT because of small cell sizes in minor allele carriers.

\section{Discussion}

Our study demonstrates that three selected FKBP5 polymorphisms moderate the association of ELS on insulin and glucose values at fasting state and/or during an OGTT in midlife. These polymorphisms, rs1360780, rs9394309, and rs9470080, are in high LD, belong to one haploblock (12), and have been previously linked with risk of depression (15-17) and PTSD (2) in adulthood following ELS; rs1360780 has also been associated with HPA-axis activity in adults and infants $(13,14)$. In our study among carriers of at least one copy of the minor allele, those who had been exposed to ELS had higher insulin values at fasting and 30-minutes after the glucose load, higher incremental and the AUC insulin and higher odds for IFG, compared with carriers not exposed to ELS. No such differences in these glycemic traits were found in carriers homozygous for the major allele. These findings were further confirmed by the haplotype analyses in which a haplotype formed by these three SNPs interacted with ELS in predicting the quantitative glycemic traits: carriers of the haplotype formed by the minor alleles had higher levels of fasting, 30 min and incremental insulin if they were separated in comparison to those who were not. 
These findings were not explained by sex of the participant, age, BMI, depressive symptoms, stressful life events measured at the testing in midlife, father's occupational status in childhood, own maximum attained education in adulthood, MDS components controlling for population stratification, or their interactions with the SNPs and ELS (29). Yet, when we made adjustments for antidiabetic medication use and physician-diagnosed diabetes, only the ELS $\times$ rs1360780 and ELS $\times$ haplotype interactions on fasting insulin remained significant; though in these analyses also these two interactions became significant on insulin resistance. Our findings, thus, suggest that ELS is associated with higher insulin and glucose values in midlife if we do not take into account their antidiabetic medication use and T2D diagnosis, and with higher insulin and insulin resistance values when we do, in individuals genetically vulnerable to HPA axis dysregulation.

We did not, however, find $G \times E$ interactions in the analyses of T2D or CVD. Instead, the risks of CVD and IGT were significantly higher and T2D trended to be higher for individuals exposed to ELS (3) regardless of their genetic vulnerability to HPA axis dysregulation by the FKBP5. This may suggest that the three selected FKBP5 polymorphisms, even though related to HPA axis reactivity, offer a perspective that grasps only a surface of the pathways that may explain the ELS - manifest disease associations. Indeed, both diabetes and CVD are complex polygenic aging-related disorders. Future $G \times$ E studies using the genome-wide approach (35) in much larger samples than ours may unravel the presumably complex genetic pathways via which ELS may exert effects on manifest T2D and CVD. Such studies will, however, need to concur challenges that not only relate to the sample size but also to ELS exposures that are quantitatively and qualitatively comparable across individuals.

As we did, however, find significant $G \times E$ interactions on higher levels of quantitative glycemic traits, which predict increased risk of future T2D and CVD (21), we 
cannot rule out that another explanation for the lack of significant $G \times E$ interactions on T2D and CVD relates to the still relatively young age of the sample, and consequently small number of individuals with manifest disease decreasing statistical power to detect significant associations. Future follow-up studies of this cohort will tell if the increased risk in the genetically vulnerable individuals exposed to ELS will translate into manifest disease as the participants of our cohort age.

Furthermore, elevated concentrations of insulin, which we observed in the participants with minor alleles in rs1360780, rs9394309, and rs9470080 and a haplotype formed from these alleles who also experienced ELS, may be an indication of compensatory hyperinsulinemia - increased insulin secretion in $\beta$ cells in an attempt to overcome insulin resistance (6). However, if not controlled, after a period of compensatory hyperinsulinemia with normal glucose tolerance, $\beta$ cell insulin secretion declines, insulin receptors get downregulated, and IGT and eventually overt T2D may result (36). Therefore, follow-up studies of HBCS participants are essential to see, if this transition occurs, particularly in those who carry the environmental and genetic risks.

Two potential pathways may account for these findings. First, chronic or repeated exposure to stress (or a single exposure to severe stress) and associated elevated levels of stress hormones, can lead to increased portal and peripheral free fatty acids, impaired ability of insulin to translocate intracellular SLC2A4 glucose transporters to the cell surface, and insulin hypersecretion $(37,38)$. These effects lead to long-term metabolic consequences, which include hypertension, metabolic syndrome, insulin resistance, and T2D (38). When stress is experienced in the early stages of development, it may lead to attenuated development of the hippocampus and amygdala, areas that have a high density of glucocorticoid receptors and persistent postnatal neurogenesis (39) and that are implicated in T2D $(37,38)$. Childhood trauma may also exert its effect via impacting DNA 
methylation and, subsequently, the function of genes later in life (40). A recent study supports this interpretation as patterns of DNA demethylation for the FKBP5 rs 1360780 SNP in the whole blood were linked to early childhood adversity (41). Thus, in combination with preexisting genetic vulnerability, chronic alterations in the activity of the stress system early in life may have permanent effects on brain development and endocrine and metabolic systems $(38,39)$.

Alternatively, presence of risk alleles in FKBP5 gene in combination with ELS may disrupt mammalian target of rapamycin (mTOR) signaling pathway, which integrates signals from nutrients, growth factors (including insulin), and information on energy status to regulate many processes in the organism $(42,43)$. mTOR is an atypical serine/ threonine protein kinase that interacts with several proteins to form two distinct complexes - mTOR complex 1 (mTORC1) and 2 (mTORC2) (42). Animal studies indicate that the glucose uptake, insulin sensitivity and animal growth in vivo are dependent on both mTOR complexes (44). Heightened mTORC2 signals were associated with insulin resistance due to mTORC2-mediated degradation of insulin receptor substrate-1 (IRS-1) (45). Importantly, both mTORC1 and mTORC2 are partly regulated by FKBP family proteins $(46,47)$. In turn, elevated glucocorticoids in the hippocampus, which are associated with ELS exposure (39), were demonstrated to have direct effect on mTOR signaling pathway in mice, with significant reduction in hippocampal mTOR protein in the animals with a previous history of stress (43). As FKBP5 is associated with both mTOR regulation (47) and GR activity (12), $\mathrm{G} \times \mathrm{E}$ interaction in this region on metabolic outcomes is plausible.

Strengths of our study relate to the longitudinal study design, relatively large sample size, objectively recorded ELS augmented by self-report, and clinical measurement of glucose tolerance. Moreover, we were able to take into account several potential covariates. Nevertheless, some limitations should be addressed. First, the experience of 
early childhood separation may have varied from negative to positive. This remains an unavoidable study limitation as we do not have data on the ELS experience, and any adulthood recall of events in childhood is at least to some extent biased. Further, staying in Finland during the war with one's parent(s) may have been equally or even more stressful than the separation from one's parent(s). However, both the separated and the non-separated participants were exposed to war in childhood, because none of the children were evacuated before the war broke out, and some of the separated children returned home during the war. Hence, our findings may offer a rather conservative estimate of the differences between the separated and the non-separated groups. We cannot rule out that an explanation for a lack of significant GxE interactions for some of our outcomes lies in the sample size. Therefore, even though we also found significant GxE interactions on fasting insulin and/or HOMA-IR when we specified the ELS exposure further by length of and age at separation, these associations should be interpreted with caution. While post-hoc power calculations are generally not recommended, as they always demonstrate low power $(<50 \%)$ with respect to a nonsignificant or nominally significant associations $(48,49)$, our findings encourage future studies to test these interaction associations in larger samples. Finally, when we made corrections for multiple testing only interactions with fasting and/or incremental insulin remained. Also this finding encourages further studies with larger samples sizes.

To conclude, our study shows that the association between ELS and quantitative glycemic traits was dependent on the three selected FKBP5 SNPs (rs1360780, rs9394309, and rs9470080) and their haplotype. ELS predicted higher values in those with minor alleles in any or all of these SNPs whereas ELS was not associated with insulin or glucose levels in those homozygous for major allele. Our findings support the role for HPA axis dysregulation in health-related metabolic outcomes. 


\section{Acknowledgements}

Funding for this study was provided by the Academy of Finland, Graduate School of

Psychology, Learning and Education, University of Helsinki Research Funds, FraNet, Alfred Kordelin foundation, Ella and Georg Ehrnrooths Stiftelse, and Yrjö Jahnsson Foundation.

\section{References}

1. Pesonen AK, Räikkönen K, Heinonen K, Kajantie E, Forsén T, Eriksson JG. Depressive symptoms in adults separated from their parents as children: A natural experiment during World War II. Am J Epidemiol 2007;166(10):1126-33.

2. Binder EB, Bradley RG, Liu W, Epstein MP, Deveau TC, Mercer KB, Tang Y, Gillespie CF, Heim CM, Nemeroff CB, Schwartz AC, Cubells JF, Ressler KJ. Association of FKBP5 polymorphisms and childhood abuse with risk of posttraumatic stress disorder symptoms in adults. JAMA 2008;299(11):1291-305.

3. Alastalo H, Raikkonen K, Pesonen A-K, Osmond C, Barker DJP, Kajantie E, Heinonen K, Forsen TJ, Eriksson JG. Cardiovascular health of Finnish war evacuees 60 years later. Ann Med 2009;41(1):66-72.

4. Huang H, Yan P, Shan Z, Chen S, Li M, Luo C, Gao H, Hao L, Liu L. Adverse Childhood Experiences and Risk of Type 2 Diabetes: A Systematic Review and Meta-analysis. Metabolism 2015; 64 (11): 1408-18.

5. Danese A, Tan M. Childhood maltreatment and obesity: systematic review and meta-analysis. Mol Psychiatry 2014;19(5):544-54 . 
6. Hupfeld CJ, Olefsky JM. Type 2 Diabetes Mellitus: Etiology, Pathogenesis, and Natural History. In: Jameson JL, De Groot LJ. Endocrinology: Adult and Pediatric.7th ed. Philadelphia: Elsevier Saunders; 2013. p. 691-714.

7. Rosmond R, Björntorp P. The hypothalamic-pituitary-adrenal axis activity as a predictor of cardiovascular desease, type 2 diabetes and stroke. J of Internal Med 2000; 247: 188-197.

8. Reynolds RM, Syddall HE, Walker BR, Wood PJ, Phillips DIW. Predicting cardiovascular risk factors from plasma cortisol measured during oral glucose tolerance test. Metablism 2003; 52 (5): 524-27.

9. Schoorlemmer RMM, Peeters GMEE, van Schoor NM, Lips P. Relationships between cortisol level, mortality and chronic diseases in older persons. Clin Endocrinology 2009; 71: 779-86.

10. Binder EB, Salyakina D, Lichtner P, Wochnik GM, Ising M, Pütz1 B, Papiol S, Seaman S, Lucae1 S, Kohli MA, Nickel T, Künzel HE, Fuchs B, Majer M, Pfennig A, Kern N, Brunner J, Modell S, Baghai T, Deiml T, Zill P, Bondy B, Rupprecht R, Messer T, Köhnlein O, Dabitz H, Brückl T, Müller N, Pfister H, Lieb R, Mueller JC, Lõhmussaar E, Strom TM, Bettecken T, Meitinger T, Uhr M, Rein T, Holsboer F, Müller-Myhsok B. Polymorphisms in FKBP5 are associated with increased recurrence of depressive episodes and rapid response to antidepressant treatment. Nat Genet 2004; 36: 1319-25.

11. Hubler TR, Scammell JG. Intronic hormone response elements mediate regulation of FKBP5 by progestins and glucocorticoids. Cell Stress Chaperones 2004; 9: 243-52. 
12. Zannas AS, Binder EB. Gene-envirnment interactions at the FKBP5 locus: sensitive periods, mechanisms and pleiotropism. Genes, Brain and Behavior 2014; 13: 25-37.

13. Ising M, Depping AM, Siebertz A, Lucae S, Unschuld PG, Kloiber S, Horstmann S, Uhr M, Müller-Myhsok B,Holsboer F. Polymorphisms in the FKBP5 gene region modulate recovery from psychosocial stress in healthy controls. Eur $\mathrm{J}$ Neurosci 2008; 28: 389-98.

14. Luijk MP, Velders FP, Tharner A, van ljzendoorn MH, Bakermans-Kranenburg MJ, Jaddoe VW, Hofman A, Verhulst FC, Tiemeier H. FKBP5 and resistant attachment predict cortisol reactivity in infants: gene-environment interaction. Psychoneuroendocrinology 2010; 35: 1454-61.

15. Appel K, Schwahn C, Mahler J, Schulz A, Spitzer C, Fenske K, Stender J, Barnow S, John U, Teumer A, Biffar R, Nauck M, Volzke H, Freyberger HJ, Grabe HJ. Moderation of Adult Depression by a Polymorphism in the FKBP5 Gene and Childhood Physical Abuse in the General Population. Neuropsychopharmacology. 2011;36(10):1982-91.

16. Lahti J, Ala-Mikkula H, Kajantie E, Haljas K, Eriksson JG, Räikkönen K. Associations between self-reported and objectively recorded early life stress, FKBP5 polymorphisms and depressive symptoms in midlife. Biol Psychiatry 2015; S00063223(15): 00920-8.

17. Zimmermann P, Brückl T, Nocon A, Pfister H, Binder EB, Uhr M, Lieb R, Moffitt TE, Caspi A, Holsboer $\mathrm{F}$, Ising M. Interaction of FKBP5 gene variants and adverse life events in predicting depression onset: results from a 10-year prospective community study. Am J Psychiatry 2011;168(10):1107-16. 
18. Lessard J, Holman EA. FKBP5 and CRHR1 polymorphisms moderate the stressphysical health association in a national sample. Heal Psychol 2014;33(9):1046-56.

19. Barker DJP, Osmond C, Forsén TJ, Kajantie E, Eriksson JG. Trajectories of growth among children who have coronary events as adults. $\mathrm{N}$ Engl $\mathrm{J}$ Med. 2005;353(17):1802-9.

20. Eriksson JG, Osmond C, Kajantie E, Forsen TJ, Barker DJ. Patterns of growth among children who later develop type 2 diabetes or its risk factors. Diabetologia 2006;49:2853-8.

21. WHO. Definition and Diagnosis of Diabetes Mellitus and Intermediate Hyperglycemia. Geneva: World Health Organization; 2006.

22. Matthews DR, Hosker JP, Rudenski AS, Naylor BA, Treacher DF, Turner RC. Homeostasis model assessment: insulin resistance and beta-cell function from fasting plasma glucose and insulin concentrations in man. Diabetologia. 1985;28(7):412-9.

23. Matsuda M, DeFronzo RA. Insulin sensitivity indices obtained from oral glucose tolerance testing: Comparison with the euglycemic insulin clamp. Diabetes Care 1999;22(9):1462-70.

24. Reaven GM, Brand RJ, Chen YD, Mathur AK, Goldfine I. Insulin resistance and insulin secretion are determinants of oral glucose tolerance in normal individuals. Diabetes. 1993;42(9):1324-32.

25. Kavén P. Humanitaarisuuden varjossa: Poliittiset tekijät lasten- siirroissa Ruotsiin sotiemme aikana ja niiden jälkeen [In the shadow of humanity: Political factors in the 
evacuations of children to Sweden during World War II] Helsinki, Finland: Doctoral dissertation, University; 2010.

26. Hardt J, Rutter M. Validity of adult retrospective reports of adverse childhood experiences: Review of the evidence. J Child Psychol Psychiatry Allied Discip. 2004;45(2):260-73.

27. Anderson RJ, Freedland KE, Clouse RE, Lustman PJ. The Prevalence of Comorbid Depression. Diabetes Care 2001;24(6):1069-78.

28. Berge LI, Riise T. Comorbidity between Type 2 Diabetes and Depression in the Adult Population: Directions of the Association and Its Possible Pathophysiological Mechanisms. Int J Endocrinol 2015;2015:1-7.

29. Pyykkönen A-J, Räikkönen K, Tuomi T, Eriksson JG, Groop L, Isomaa B. Depressive symptoms, antidepressant medication use, and insulin resistance: the PPP-Botnia Study. Diabetes Care 2011;34(12):2545-7.

30. Beck a T, Ward CH, Mendelson M, Mock J, Erbaugh J. An inventory for measuring depression. Arch Gen Psychiatry 1961;4:561-71.

31. Pyykkönen A-J, Räikkänen K, Tuomi T, Eriksson J, Groop L, Isomaa B. Stressful Life Events and the Metabolic Syndrome. Diabetes Care 2010;33(2):378-84.

32. Keller MC. Gene $\times$ environment interaction studies have not properly controlled for potential confounders: The problem and the (simple) solution. Biol Psychiatry 2014;75(1):18-24. 
33. Barrett JC, Fry B, Maller J, Daly MJ. Haploview: Analysis and visualization of LD and haplotype maps. Bioinformatics 2005;21(2):263-5.

34. Schaid DJ, Rowland CM, Tines DE, Jacobson RM, Poland G a. Score tests for association between traits and haplotypes when linkage phase is ambiguous. Am J Hum Genet 2002;70(2):425-34.

35. Almli LM, Duncan R, Feng H, Ghosh D, Binder EB, Bradley B, Ressler KJ, Conneely $\mathrm{KN}$, Epstein MP. Correcting systematic inflation in genetic association tests that consider interaction effects: application to a genome-wide association study of posttraumatic stress disorder. JAMA psychiatry 2014;71(12):1392-9.

36. Warram JH, Martin BC, Krolewski AS, Soeldner JS, Kahn CR. Slow glucose removal rate and hyperinsulinemia precede the development of type II diabetes in the offspring of diabetic parents. Annals of internal medicine 1990; 113(12): 909-15.

37. Moulton CD, Pickup JC, Ismail K. Depression and diabetes 2 The link between depression and diabetes: the search for shared mechanisms. LANCET Diabetes Endocrinol 2015;3(6):461-71.

38. Pervanidou P, Chrousos GP. Metabolic consequences of stress during childhood and adolescence. Metabolism 2012;61(5):611-9.

39. Lupien SJ, McEwen BS, Gunnar MR, Heim C. Effects of stress throughout the lifespan on the brain, behaviour and cognition. Nat Rev Neurosci 2009;10(6):43445. 
40. Vinkers $\mathrm{CH}$, Kalafateli AL, Rutten BP, Kas MJ, Kaminsky Z, Turner JD, Boks MP. Traumatic stress and human DNA methylation: a critical review. Epigenomics 2015;7(4):593-608.

41. Klengel T, Mehta D, Anacker C, Rex-haffner M, Jens C, Pariante CM, Pace TW, Mercer KB, Mayberg HS, Bradley $\quad$ B, Nemeroff $\quad$ CB, Holsboer F, Heim CM, Ressler KJ, Rein T, Binder EB. Allele-specific FKBP5 DNA demethylation mediates gene-childhood trauma interactions. Nat Neurosci. 2013;16(1):33-41.

42. Laplante M, Sabatini DM. mTOR signaling in growth control and disease. Cell 2013; 149(2):274-93.

43. Polman JA, Hunter RG, Speksnijder N, van den Oever JM, Korobko OB, McEwen BS, de Kloet ER, Datson NA. Glucocorticoids Modulate the mTOR Pathway in the Hippocampus: Differential Effects Depending on Stress History. Endocrinology. 2012;153(9):4317-27.

44. Zhu H, Shyh-Chang N, Segrè AV, Shinoda G, Shah SP, Einhorn WS, Takeuchi A, Engreitz JM, Hagan JP, Kharas MG, Urbach A, Thornton JE, Triboulet R, Gregory RI; DIAGRAM Consortium; MAGIC Investigators, Altshuler D, Daley GQ. The Lin28/let-7 axis regulates glucose metabolism. Cell. 2011;147(1):81-94.

45. Kim SJ, DeStefano M a., Oh WJ, Wu CC, Vega-Cotto NM, Finlan M, Liu D, Su B, Jacinto E. mTOR Complex 2 Regulates Proper Turnover of Insulin Receptor Substrate-1 via the Ubiquitin Ligase Subunit Fbw8. Mol Cell. 2012;48(6):875-87.

46. Hoeffer CA, Tang W, Wong H, Santillan A, Patterson RJ, Martinez LA, TejadaSimon MV, Paylor R, Hamilton SL, Klann E. Removal of FKBP12 enhances mTOR- 
Raptor interactions, LTP, memory, and perseverative/repetitive behavior. Neuron 2008;60(5):832-45.

47. März AM, Fabian A-K, Kozany C, Bracher A, Hausch F. Large FK506-binding proteins shape the pharmacology of rapamycin. Mol Cell Biol 2013;33(7):1357-67.

48. Goodman SN, Berlin JA. The Use of Predicted Confidence Intervals When Planning Experiments and the Misuse of Power When Interpreting the Results. Annals Internal Medicine 1994; 121: 200-06.

49. Levine M., Ensom MHH. Post Hoc Power Analysis: An Idea Whose Time Has Passed. Pharmacotherapy 2001; 21: 405-09. 
Figure 1. Estimated marginal means for fasting insulin (Panel A), 30-minute insulin in response to oral glucose tolerance test (Panel B), incremental insulin (Panel C) and area under the curve (AUC) insulin (Panel D) for different genotypes of the FKBP5 single nucleotide polymorphism rs1360780 in those who were (separated) and who were not (not separated) to early life stress. Error bars reflect standard error (SE) of mean. Values are adjusted for sex, age and body mass index at the time of clinical exam, father's occupational status in childhood, the first three multidimensional scaling components derived from multidimensional scaling analyses performed with Plink. (A p-value $<.025$ is significant at Bonferroni-corrected level $p<.05)$.

Figure 2. Estimated marginal means for 30-minute insulin in response to oral glucose tolerance test (Panel A) and incremental insulin (Panel C) for different genotypes of the FKBP5 single nucleotide polymorphism rs93694309 in those who were (separated) and who were not (not separated) to early life stress. Error bars reflect standard error (SE) of mean. Values are adjusted for sex, age and body mass index at the time of clinical exam, father's occupational status in childhood, the first three multidimensional scaling components derived from multidimensional scaling analyses performed with Plink. (A pvalue $<.025$ is significant at Bonferroni-corrected level $p<.05)$.

Figure 3. Estimated marginal means for incremental insulin for different genotypes of the FKBP5 single nucleotide polymorphism rs9470080 in those who were (separated) and who were not (not separated) to early life stress. Error bars reflect standard error (SE) of mean. Values are adjusted for sex, age and body mass index at the time of clinical exam, father's occupational status in childhood, the first three multidimensional scaling 
components derived from multidimensional scaling analyses performed with Plink. (A pvalue $<.025$ is significant at Bonferroni-corrected level $p<.05)$. 
Panel A

$\mathrm{p}$-value (unadjusted model $)=0.049$

$\mathrm{p}$-value (adjusted model) $=0.015$

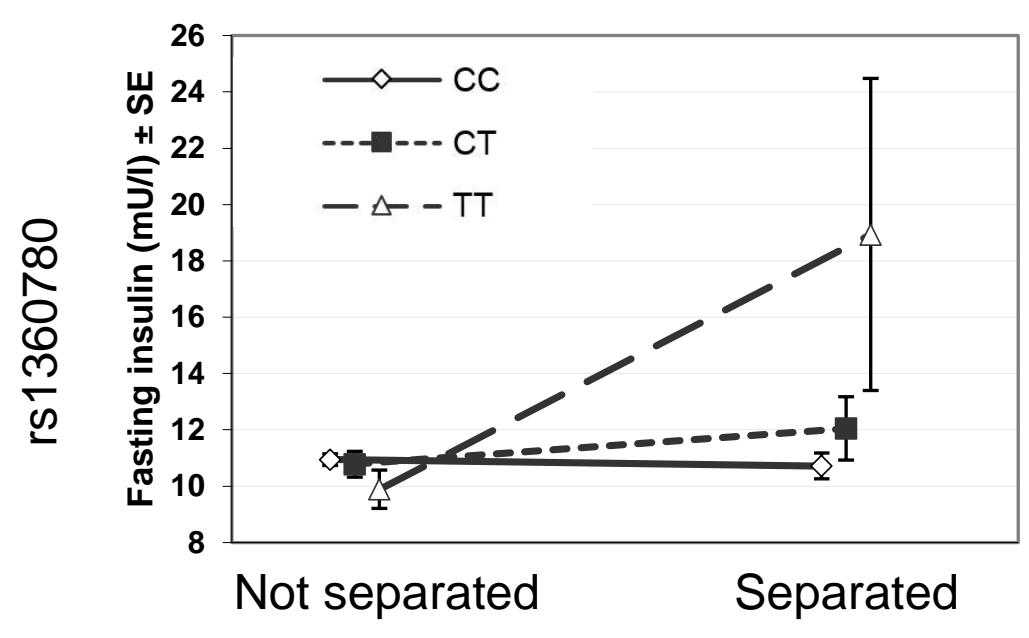

Panel C

$\mathrm{p}$-value (unadjusted model) $=0.047$

$\mathrm{p}$-value $($ adjusted model $)=0.032$

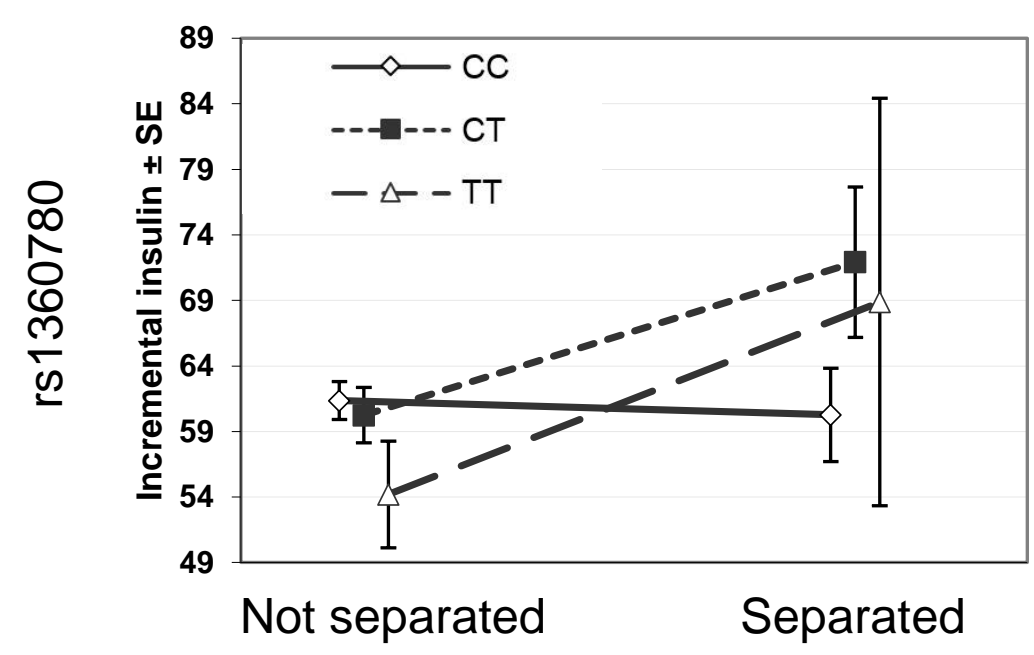

Panel B

$\mathrm{p}$-value (unadjusted model) $=0.045$

$p$-value (adjusted model $)=0.031$

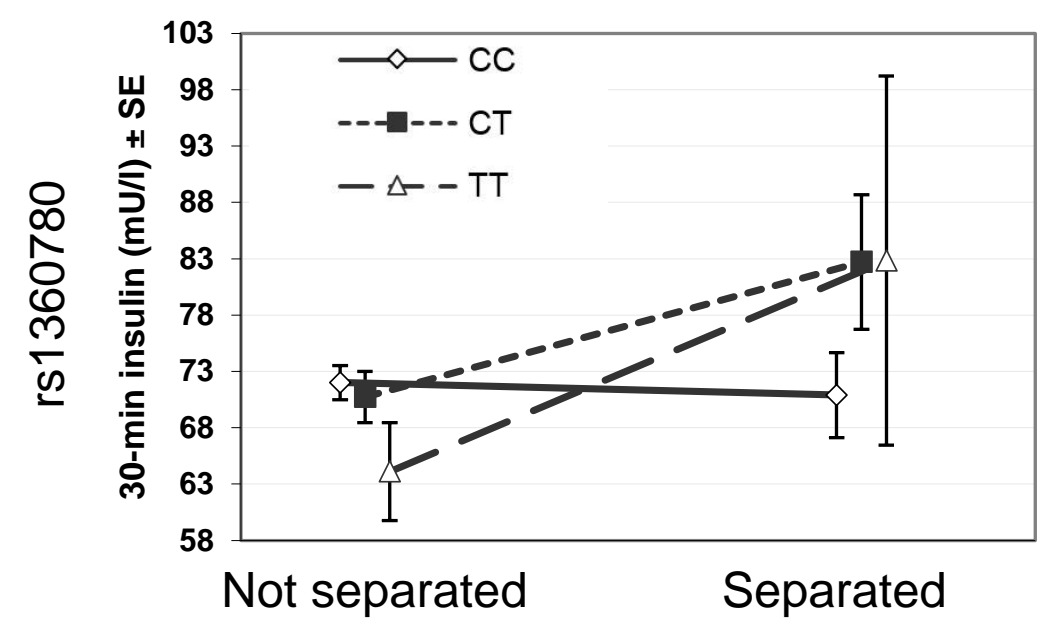

Panel D

p-value (unadjusted model) $=0.063$

$\mathrm{p}$-value (adjusted model) $=0.044$

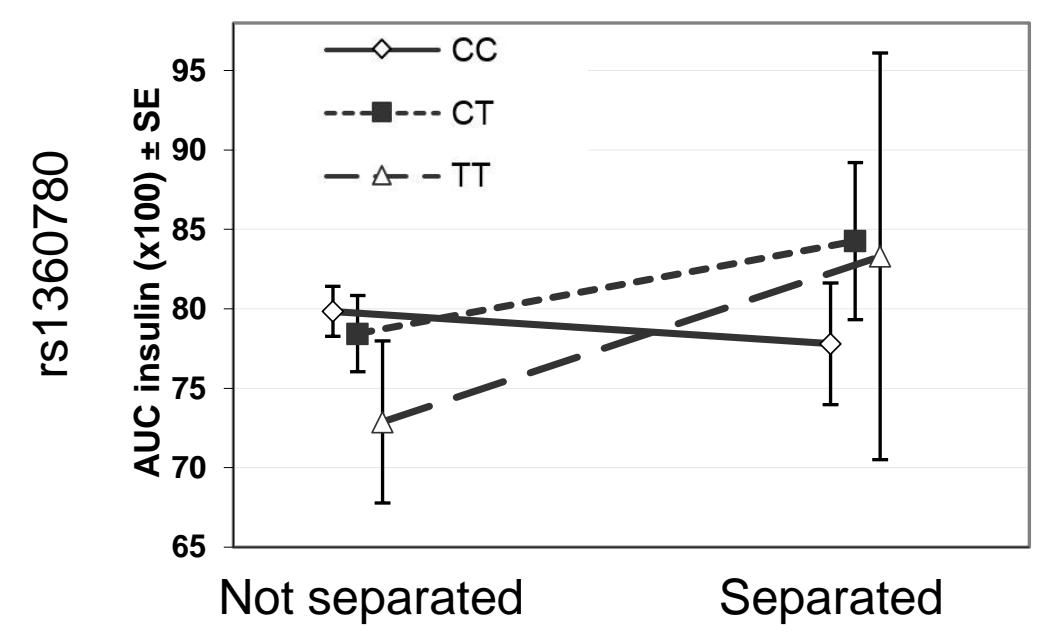




\section{Panel A}

$\mathrm{p}$-value (unadjusted model $)=0.041$

$\mathrm{p}$-value $($ adjusted model $)=0.041$

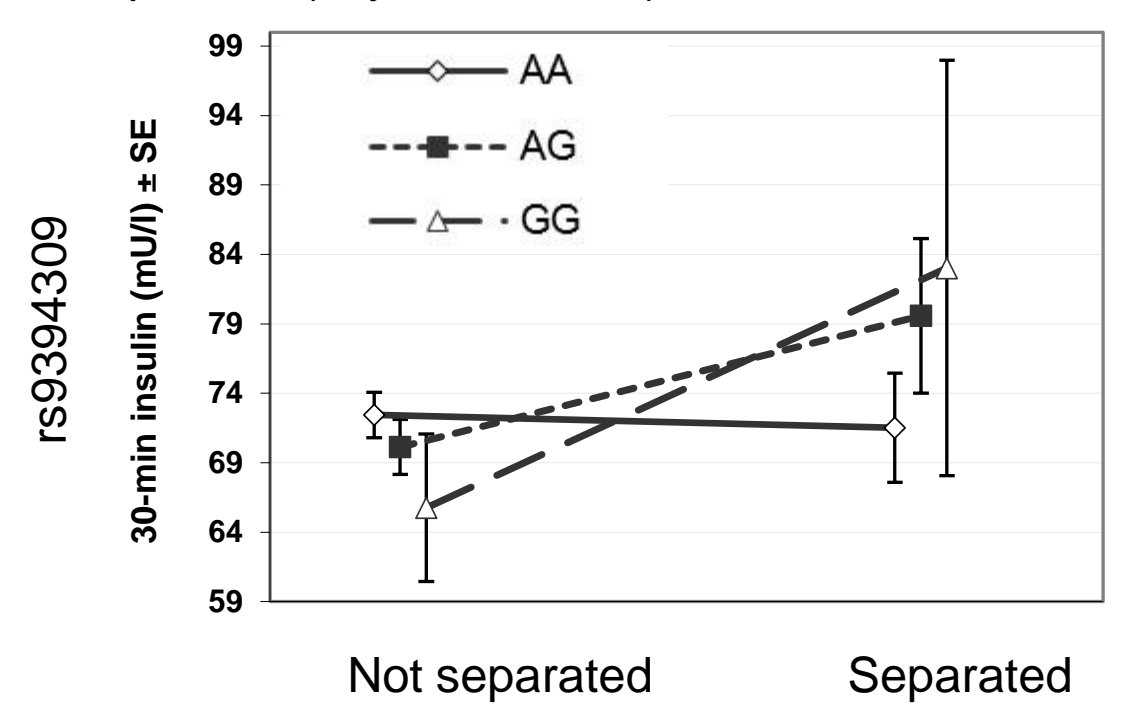

Panel B

p-value (unadjusted model $)=0.027$

$\mathrm{p}$-value (adjusted model $)=0.028$

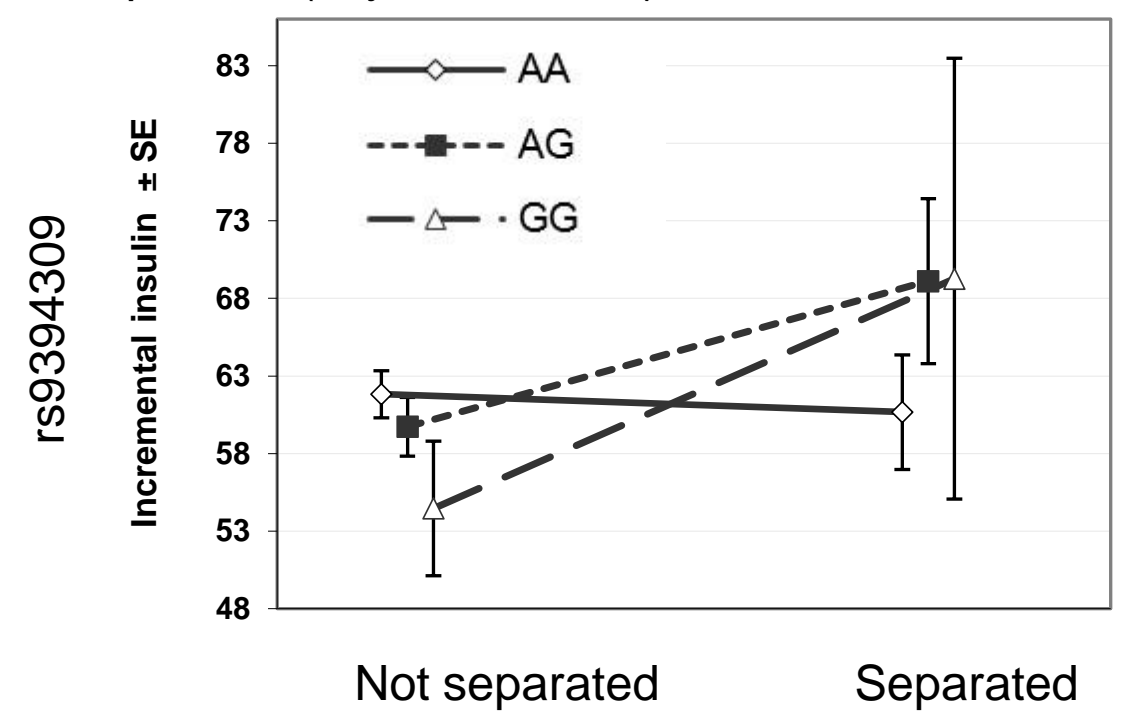


$\mathrm{p}$-value (unadjusted model) $=0.046$

$p$-value (adjusted model $)=0.043$

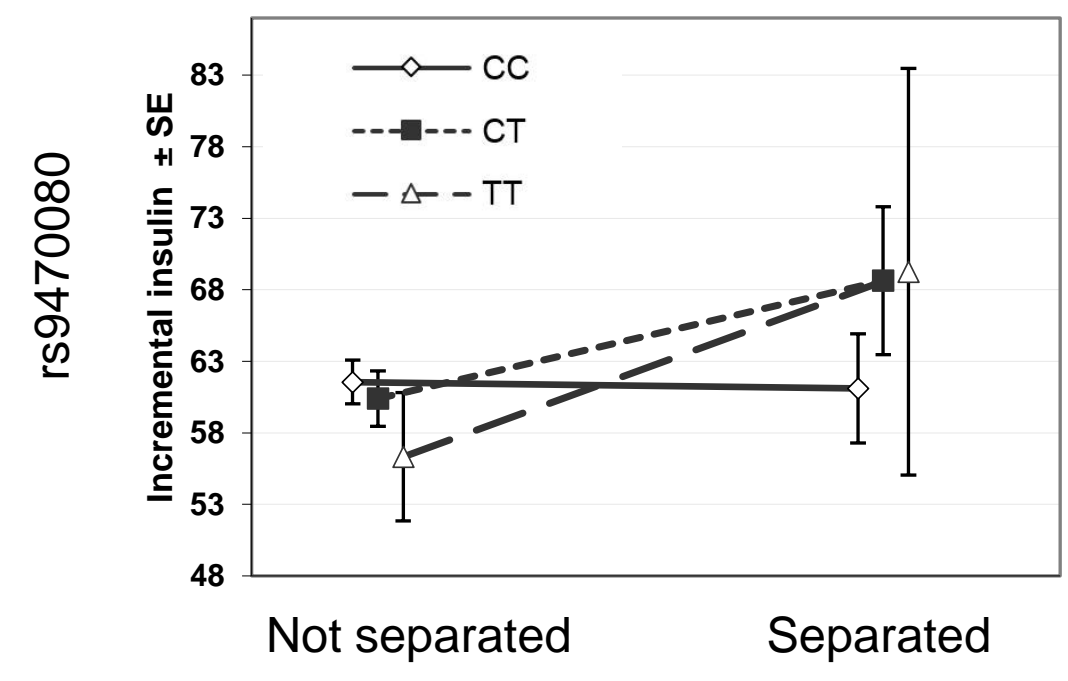


$35660 \mathrm{~K} \quad 35680 \mathrm{~K} \quad 3570$

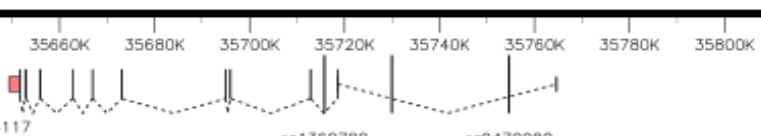

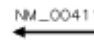

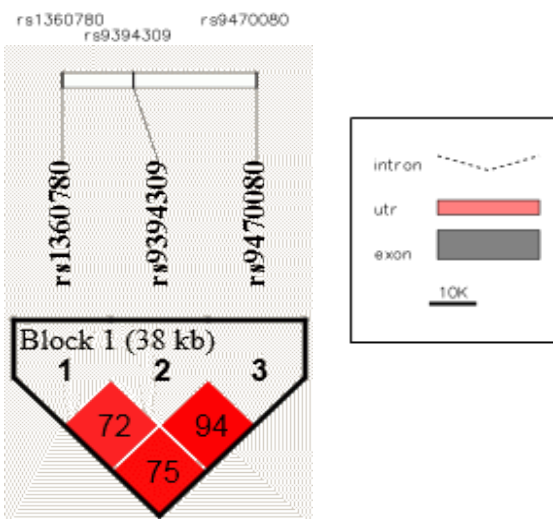

Supplemental figure 1:

Overview of FKBP5 gene structure and linkage

disequilibrium plot according to solid spine

algorithm with default values of three SNPs in the

FKBP5 locus (numbers presented in the figure are

R-squared -values). Figure drawn with FancyGene

accessed 30.3.2015 [http://bio.ieo.eu/fancygene/]

by using UCSC Genome Browser locations on

Human Mar. 2006 Assembly (hg18)) and

Haploview 4.2. 
Table 1. Characteristics of the sample according to separation status.

\begin{tabular}{|c|c|c|c|}
\hline & $\begin{array}{l}\text { Non- } \\
\text { separated } \\
(n=1455)\end{array}$ & $\begin{array}{l}\text { Separated } \\
(n=273)\end{array}$ & \\
\hline Characteristics: & $\begin{array}{l}\mathrm{N}(\%) \text { or } \\
\text { Mean } \\
\text { (standard } \\
\text { deviation) }\end{array}$ & $\begin{array}{l}\mathrm{N}(\%) \text { or } \\
\text { Mean } \\
\text { (standard } \\
\text { deviation) }\end{array}$ & $P$ \\
\hline Sex: women & $843(57.9)$ & $148(54.2)$ & .14 \\
\hline Age (years) & $61.1(2.8)$ & $63.7(2.8)$ & $<.001$ \\
\hline $\begin{array}{l}\text { Father's occupational } \\
\text { status in childhood }\end{array}$ & & & .15 \\
\hline Manual worker & $915(63.4)$ & $183(67.8)$ & \\
\hline Junior clerical & $303(21.0)$ & $57(21.1)$ & \\
\hline Senior clerical & $226(15.7)$ & $30(11.1)$ & \\
\hline Maximum attained lev & & & \\
\hline $\begin{array}{l}\text { of education in } \\
\text { adulthood }\end{array}$ & & & .055 \\
\hline $\begin{array}{l}\text { Basic/primary or } \\
\text { less }\end{array}$ & 469 (32.3) & $110(40.3)$ & \\
\hline Lower secondary & $282(19.4)$ & $53(19.4)$ & \\
\hline Upper secondary & $383(26.4)$ & $58(21.2)$ & \\
\hline Tertiary & $318(21.9)$ & $52(19.0)$ & \\
\hline BMI (kg/m2) & $27.7(4.8)$ & $27.8(4.3)$ & .72 \\
\hline BDI sum score & $5.8(5.2)$ & $6.0(4.9)$ & .42 \\
\hline
\end{tabular}




\begin{tabular}{llll}
\hline SLE in the past 12 & & & \\
months (mean number & $1.3(1.8)$ & $1.2(1.7)$ & .52 \\
of events) & & & \\
Antidiabetic & $99(6.8)$ & $17(6.2)$ & .42 \\
medication: yes & & & \\
Physician-diagnosed & $110(7.6)$ & $21(7.7)$ & .51 \\
T2D & & & \\
T2D & $217(14.9 \%)$ & $51(18.8 \%)$ & .069 \\
CVD & $116(8.0)$ & $40(14.7)$ & .001
\end{tabular}

Glucose (mmol/l)

$\begin{array}{llll}\text { Fasting } & 5.9(1.4) & 5.8(1.0) & .40 \\ \text { 30-minute } & 9.4(2.2) & 9.6(2.1) & .32 \\ \text { 2-hour } & 7.8(3.4) & 8.1(3.3) & .25 \\ & 1004.6 & 1024.4 & \\ \text { AUC } & (274.4) & (263.3) & .28 \\ \text { IFG } & 196(15.8 \%) & 35(15.8 \%) & .53 \\ \text { IGT } & 352(28.4 \%) & 76(34.4 \%) & .045\end{array}$

$\underline{\text { Insulin (mU/l) }}$

$\begin{array}{llll}\text { Fasting } & 10.5(8.7) & 11.0(9.8) & .36 \\ \text { 30-minute } & 71.2(48.0) & 75.8(52.6) & .17 \\ \text { 2-hour } & 76.7(64.8) & 77.2(59.9) & .89 \\ & 7871.8 & 8178.4 & \\ \text { AUC } & (5168.4) & (5050.7) & .37 \\ \text { Incremental } & 61.1(44.3) & 65.4(49.2) & .16 \\ \text { ISI } & 5.4(3.7) & 5.1(3.3) & .37\end{array}$




$\begin{array}{llll}\text { HOMA } & 2.9(2.9) & 2.9(2.5) & .97 \\ \text { FKBP5 polymorphisms } & & & .88 \\ \text { rs1360780 } & & & \\ \text { CC } & 895(61.9) & 172(63.1) & \\ \text { CT } & 486(33.6) & 87(32.1) & \\ \text { TT } & 64(4.4) & 12(4.4) & \\ \text { rs9394309 } & & & \\ \text { AA } & 831(57.2) & 163(59.7) & \\ \text { AG } & 543(37.4) & 97(35.5) & \\ \text { GG } & 78(5.4) & 13(4.8) \\ \text { rs9470080 } & & \\ \text { CC } & 794(55.1) & 157(58.1) & \\ \text { CT } & 562(39.0) & 100(37.0) & \\ \text { TT } & 85(5.9) & 13(4.8)\end{array}$


Table 2. Mean differences in glycemic traits in individuals who were and were not exposed to ELS according to the genotypes of the three selected FKBP5 SNPS.

\begin{tabular}{|c|c|c|c|c|c|c|c|c|c|c|c|c|}
\hline \multirow[b]{2}{*}{ FKBP5 SNPS: } & \multicolumn{3}{|c|}{ Fasting insulin } & \multicolumn{3}{|c|}{ 30-minute insulin } & \multicolumn{2}{|c|}{ Incremental insulin } & \multicolumn{4}{|c|}{ AUC insulin } \\
\hline & $\begin{array}{l}\text { Mean } \\
\text { difference } \\
(\%)\end{array}$ & $95 \% \mathrm{Cl}^{\mathrm{a}}$ & $p$ & $\begin{array}{l}\text { Mean } \\
\text { differenc } \\
\text { e }(\%)\end{array}$ & $95 \% \mathrm{Cl}^{\mathrm{a}}$ & $p$ & $\begin{array}{l}\text { Mean } \\
\text { differenc } \\
\text { e }(\%)\end{array}$ & $95 \% \mathrm{Cl}^{\mathrm{a}}$ & $\mathrm{P}$ & $\begin{array}{l}\text { Mean } \\
\text { differenc } \\
\text { e }(\%)\end{array}$ & $95 \% \mathrm{Cl}^{\mathrm{a}}$ & $p$ \\
\hline \multicolumn{13}{|l|}{ rs1360780 } \\
\hline $\mathrm{CC}^{1}$ & -2.5 & $\begin{array}{l}-11.76 \text { to } \\
6.75\end{array}$ & .60 & -1.96 & -13.04 to 9.12 & .73 & -3.18 & -15.4 to 9.03 & .61 & -3.06 & -12.82 to 6.7 & .54 \\
\hline $\mathrm{CT} / \mathrm{TT}^{2}$ & 13.95 & 1.68 to 26.23 & .026 & 17.62 & 4.07 to 31.16 & .011 & 19.21 & 3.75 to 34.66 & .015 & 12.52 & 0.24 to 24.79 & .046 \\
\hline \multicolumn{13}{|l|}{ rs9394309 } \\
\hline$A^{1}$ & -1.59 & -11.08 to 7.9 & .74 & -3.08 & -14.53 to 8.38 & .60 & -5.38 & $\begin{array}{l}-17,91 \text { to } \\
7.15\end{array}$ & .40 & -3.92 & $\begin{array}{l}-14.09 \text { to } \\
6.24\end{array}$ & .45 \\
\hline $\mathrm{AG} / \mathrm{GG}^{2}$ & 10.17 & $\begin{array}{l}-1.45 \text { to } \\
21.79\end{array}$ & .086 & 15.59 & 2.78 to 28.4 & .017 & 17.98 & 3.26 to 32.71 & .017 & 9.86 & $\begin{array}{l}-1.55 \text { to } \\
21.27\end{array}$ & .090 \\
\hline \multicolumn{13}{|l|}{ rs9470080 } \\
\hline $\mathrm{CC}^{1}$ & -1.13 & -10.83 to & .82 & -2.3 & -13.99 to 9.4 & .70 & -4.78 & -17.57 to & .46 & -2.68 & -12.98 to & .61 \\
\hline
\end{tabular}




\begin{tabular}{|c|c|c|c|c|c|c|c|c|c|c|c|c|}
\hline & & 8.57 & & & & & & 8.01 & & & 7.63 & \\
\hline $\mathrm{CT} / \mathrm{TT}^{2}$ & 9.76 & -1.7 to 21.22 & .095 & 14.51 & 1.77 to 27.25 & .026 & 16.83 & 2.22 to 31.45 & .024 & 8.67 & $\begin{array}{l}-2.76 \text { to } \\
20.10\end{array}$ & .14 \\
\hline
\end{tabular}

Mean differences were log-transformed to attain normality and are presented in percentage differences between values in the individuals who were separated from parents vs those who were not. The results are presented from the models adjusted for sex, age and BMI at the time of clinical exam, father's occupational status in childhood, the first three MDS components derived from multidimensional scaling analyses performed with Plink.

${ }^{1} \mathrm{n}=951-1067,{ }^{2} \mathrm{n}=649-760$

${ }^{a}$ 95\% Confidence Interval 